\title{
Analisis Dampak Perkebunan Kelapa Sawit Terhadap Sosial dan Ekonomi Masyarakat di Kabupaten Asahan
}

\section{Analysis of the Impact of Oil Palm Plantations on the Social And Community Economy in Asahan Regency}

\author{
Muhammad Fadly Abdina \\ Program Studi Agribisnis, Fakultas Pertanian, Universitas Medan Area, Indonesia
}

Diterima: Desember 2019; Disetujui: Desember 2019; Dipublish: Desember 2019

*Coresponding Email: muhammadfadly@gmail.com

\begin{abstract}
Abstrak
Sumatera Utara memiliki luasan sekitar $14 \%$ dari total luasan perkebunan kelapa sawit di Indonesia atau urutan kedua setelah Riau dan luas areal pada tahun 2009 dapat memproduksi CPO sebesar 3,18 juta ton atau sekitar 17 \% dari total produksi CPO nasional. Peningkatan hasil produksi tanaman kelapa sawit yang terdapat di kabupaten Asahan, selayaknya dapat berbanding lurus dengan sinergitas pembangunan perkebunan kelapa sawit yang berlandaskan keberlanjutan. Pembangunan perkebunan kelapa sawit berkelanjutan (Sustainable) adalah pembangunan yang berdampak positif terhadap aspek sosial, ekonomi dan budaya masyarakat sekitar perkebunan, regional dan nasional. Analisis perbandinagn dampak dari perkembangan perkebunan kelapa sawit sebelum dan sesudah dapat dilakukan dengan menggunakan analisis Uji t terhadap kontribusi usahatani sebelum dan sesudah berkembangnya perkebunan kelapa sawit. Hasil dari analisis Uji t terhadap kontribusi usahatani sebelum dan sesudah berkembangnya perkebunan kelapa sawit ialah: Sebelum Berkembangnya Perkebunan Kelapa sawit \% pendapatan usahatani lain terhadap total pendapatan rumah tangga tani (karet, padi, ternak) sebesar 38 \%, Sesudah Berkembangnya Perkebunan Kelapa Sawit \% pendapatan usahatani kelapa sawit terhadap total pendapatan rumah tangga tani $62 \%$. Pada penelitian ini diperoleh $62 \%$ dari total pendapatan keluarga petani, sehingga dikatakan kontribusi perkebunan kelapa sawit besar sesuai dengan kriteria kontribusi 50-75 \% (besar).
\end{abstract}

Kata Kunci: Analisis Dampak Perkebunan; Kelapa Sawit; Sosial Dan Ekonomi Masyarakat

\begin{abstract}
North Sumatra has an area of around 14\% of the total area of oil palm plantations in Indonesia or second only to Riau and the total area in 2009 could produce CPO of 3.18 million tons or around 17\% of the total national CPO production. Increased production of oil palm plants found in Asahan district, should be directly proportional to the synergy of the development of oil palm plantations based on sustainability. Sustainable oil palm plantation development (Sustainable) is development that has a positive impact on the social, economic and cultural aspects of the communities around plantations, regionally and nationally. A comparative analysis of the impact of the development of oil palm plantations before and after can be done using t-test analysis of the contribution of farming before and after the development of oil palm plantations. The results of the t-test analysis of the contribution of farming before and after the development of oil palm plantations are: Before the development of oil palm plantations\% other farm income from total farm household income (rubber, rice, livestock) by 38\%, After the development of oil palm plantations\% income oil palm farming to total farm household income of 62\%. In this study, 62\% of the total income of the farming family is obtained, so it is said that the contribution of large oil palm plantations is in accordance with the contribution criteria of $50-75 \%$ (large).
\end{abstract}

Keywords: Plantation Impact Analysis; Palm oil; Social and Economic Community

How to Cite: Abdina, M.F. (2019). Analisis Dampak Perkebunan Kelapa Sawit Terhadap Sosial dan Ekonomi Masyarakat di Kabupaten Asahan. Journal of Education, Humaniora and Social Sciences (JEHSS). 2 (2): 292-304. 


\section{PENDAHULUAN}

Kelapa sawit sebagai tanaman penghasil minyak kelapa sawit (CPO - crude palm oil) dan inti kelapa sawit (PKO) merupakan salah satu primadona tanaman perkebunan yang menjadi sumber penghasil devisa non-migas bagi Indonesia. Cerahnya prospek komoditi minyak kelapa sawit dalam perdagangan minyak nabati dunia telah mendorong pemerintah Indonesia untuk memacu pengembangan areal perkebunan kelapa sawit.

Sektor minyak kelapa sawit Indonesia mengalami perkembangan yang berarti, hal ini terlihat dari total luas areal perkebunan kelapa sawit yang terus bertambah yaitu menjadi 7,3 juta hektar pada 2009 dari 7,0 juta hektar pada 2008. Sedangkan produksi minyak sawit (crude palm oil / CPO) terus mengalami peningkatan dari tahun ke tahun dari 19,2 juta ton pada 2008 meningkat menjadi 19,4 juta ton pada 2009. Sementara total ekspornya juga meningkat, pada 2008 tercatat sebesar 18,1 juta ton kemudian menjadi 14,9 juta ton sampai dengan September 2009 (Ditjen Perkebunan 2010).

Indonesia masih menempati posisi teratas sebagai negara produsen minyak kelapa sawit (CPO) terbesar dunia, dengan produksi sebesar 19,4 juta ton pada 2009. Berdasarkan total produksi tersebut diperkirakan hanya sekitar $25 \%$ sekitar 4,8 juta ton yang dikonsumsi oleh pasar domestik. Sehingga sebagai penghasil CPO terbesar di dunia, Indonesia terus mengembangkan pasar ekspor baru untuk memasarkan produksinya.

Pemerintah telah menyatakan bahwa Komoditi kelapa sawit bagi perekonomian Indonesia sangat penting sebagai sumber devisa negara, dimana permintaan dunia terhadap produk ini semakin tinggi. Hal ini diindikasikan terjadi pergeseran pasar (market) minyak nabati dunia, dari sebelumnya didominasi konsumsi minyak kedelei yang diproduksi di negara maju (Eropa) menjadi minyak sawit yang diproduksi di negara berkembang seperti Indonesia, Malaysia, Papua Nugini, Nigeria, dan Ghana.

Harga minyak mentah (crude palm oil atau CPO) yang naik di luar perkiraan juga membuat minyak sawit selalu menjadi pembicaraan sebagai substitusi minyak fosil dalam bentuk biofuel. Data-data tersebut mengukuhkan bagaimana strategisnya komoditi kelapa sawit (Elaeis guineensis Jacq) dalam perekonomian Indonesia.

Keberhasilan menjadi produsen CPO terbesar sangat membanggakan sekaligus memberikan tantangan baru. Karena saat ini hanya kelapa sawit yang berhasil mencapai prestasi tingkat dunia dan membuat Indonesia dikenal secara internasional. Tantangan baru adalah adanya "tuntutan" agar perusahaan kelapa sawit di Indonesia dibangun dan 
dikelola secara berkelanjutan (Sustainable) agar bisa bertahan menjadi penguasa minyak sawit di dunia.

Sumatera Utara merupakan salah satu proVinsi penghasil tanaman kelapa sawit terbesar di Indonesia. Usaha perkebunan kelapa sawit di Sumatera Utara merupakan kegiatan ekonomi agribisnis kelapa sawit dan tertua di Indonesia. Sumatera Utara merupakan pusat sumber penyebaran dan pembelajaran daerah-daerah lain di Indonesia.

Pada sepuluh tahun terakhir luas areal perkebunan kelapa sawit di Sumatera Utara meningkat dari sekitar 650 ribu hektar tahun 2000 menjadi 1,05 juta hektar tahun 2009 (Ditjen Perkebunan 2010). Dengan luasan tersebut, Sumatera Utara memiliki luasan sekitar $14 \%$ dari total luasan perkebunan kelapa sawit di Indonesia atau urutan kedua setelah Riau dan luas areal pada tahun 2009 dapat memproduksi CPO sebesar 3,18 juta ton atau sekitar $17 \%$ dari total produksi CPO nasional.

Uraian diatas menggambarkan bahwa perekonomian sumatera uatara dalam periode tahun 2000-2009 mengalami pertumbuhan yang semakin meningkat dari tahun ke tahun setelah bertumbuh negatif pada tahun 1998 akibat krisis ekonomi. Perekonomian Sumatera Utara mencapai pertumbuhan rata-rata 4,9 \% selama periode tahun 2000-2005 dan meningkat diatas $6 \%$ pertahun dalam periode tahun 2006-2009 (BPS Sumut 2010).

Penyumbang terbesar dalam pertumbuhan ekonomi Sumatera Utara adalah daerah-daerah sentra agribisnis kelapa sawit (Lubis \& Tinaprilla, 2017; Bangun, 2013; Rahman \& Sembiring, 2017; Arman, Hariyadi \& Sunito, 2017). Pada tahun 2008 misalnya, sekitar $76 \%$ dari pertumbuhan ekonomi Sumatera Utara disumbang oleh daerah sentra agribisnis kelapa sawit (BPS Sumut 2010). Adapun daerah-daerah sentara utama agribisnis kelapa sawit ialah Medan, Langkat, Asahan, Deli Serdang, Serdang Bedagai, Simalungun, Batubara, dan Labuhan Batu (Ditjen Perkebunan 2010).

Salah satu kabupaten penghasil kelapa sawit yang terdapat di Sumatera utara ialah kabupaten Asahan. Kabupaten Asahan memiliki luasan perkebunan kelapa sawit sebesar 157.857 hektar, hal ini mengukuhkan Kabupaten Asahan sebagai daerah yang memiliki luasan kebun kelapa sawit terbesar kedua di Sumatera Utara setelah Labuhan Batu dengan luasan sebesar 287.582 hektar (BPS Sumut 2008) 
Vol 2, No. 2, Desember 2019, DOI: https://doi.org/10.34007/iehss.v2i2.109

Berdasarkan data yang diperoleh dari Badan Pusat Statistik (BPS) Kabupaten Asahan tahun 2011, tercatat bahwa hasil perkebunan kelapa sawit menghasilkan produksi tertinggi dibanding tanaman perkebunan lainnya pada tahun 2008 - 2010 . Uraian hasil produksi perkebunan Kabupaten Asahan terdapat pada Tabel 1.

Tabel 1. Tanaman Perkebunan Rakyat Kab.Asahan (Ton) Tahun 2008 - 2010

\begin{tabular}{|c|c|c|c|c|}
\hline No & Uraian & Tahun 2008 & 2009 & 2010 \\
\hline 1 & Karet & 11.62 & 8.80 & 16.28 \\
\hline 2 & Kelapa Sawit & 680.89 & 203.86 & 213.14 \\
\hline 3 & Kelapa & 84.02 & 38.62 & 28.70 \\
\hline 5 & Coklat & 57.82 & 7.07 & 5.82 \\
\hline
\end{tabular}

Sumber : Asahan Dalam Angka, 2011

Berdasarkan uraian Tabel 1. Terlihat bahwa produksi tanaman perkebunan kelapa sawit Kabupaten Asahan merupakan produksi terbesar pada tahun 2008 - 2010. Data Hasil perkebunan kelapa sawit terjadi penurunan pada tahun 2009 sebesar 477 ton atau 70\% dari tahun 2008. Sedangkan pada tahun 2010 terjadi peningkatan produksi dari tahun 2009 sebesar 9,28 ton atau $5 \%$.

Peningkatan hasil produksi tanaman kelapa sawit yang terdapat di kabupaten Asahan, selayaknya dapat berbanding lurus dengan sinergitas pembangunan perkebunan kelapa sawit yang berlandaskan keberlanjutan. Pembangunan perkebunan kelapa sawit berkelanjutan (Sustainable) adalah pembangunan yang berdampak positif terhadap aspek sosial, ekonomi dan budaya masyarakat sekitar perkebunan, regional dan nasional (Kadir, 2018a; Kadir, 2018b).

Aspek permasalahan sosial yang berpotensi muncul, yaitu potensi konflik dan masalah kesenjangan akses ekonomi antara masyarakat setempat dengan pendatang, serta antara masyarakat dengan pihak perkebunan besar (Setiawan, \& Sengadji, 2016; Rahmanta \& Sihombing, 2008; Siregar, 2016). Bagaimana mengelola potensi konflik agar berdampak positif bagi kesejahteraan rakyat dan bagaimana pemberdayaan masyarakat yang perlu dikembangkan untuk menumbuhkan keserasian hidup antar berbagai pihak yang berinteraksi dalam pemanfaatan sumberdaya lokal terkait dengan pengembangan perkebunan kelapa sawit ke depan.

Pada tingkat yang paling dasar, kesejahteraan manusia yang beradab adalah kemampuan manusia untuk memenuhi kebutuhan dasarnya, yaitu: kecukupan pangan, sandang, papan, kesehatan dan pendidikan (Sumardjo, 2010). Apabila kebutuhan 
dasarnya tersebut terpenuhi, kondisi tersebut dapat dikatakan sebagai kondisi aman pertama dalam kesejahteraan manusia.

Faktanya, perilaku manusia itu sendiri sering kurang kondusif bagi upaya mewujudkan kesejahteraan mereka, baik secara individu, keluarga maupun masyarakat, sehingga menyebabkan kesenjangan dalam upaya mewujudkan kesejahteraannya. Disinilah peran pemerintah terutama dan pihak-pihak terkait adalah mengembangkan suasana yang kondusif bagi upaya-upaya mewujudkan kesejahteraan sosial secara beradab dan berkeadilan.

Oleh karenanya pada penelitian ini akan menganalisis dampak-dampak sosial negatif maupun positif yang diprediksikan akan terjadi sebagai akibat dari operasional perkebunan terhadap sosial dan ekonomi masyarakat yang berada di Kabupaten Asahan.

\section{METODE PENELITIAN}

Penelitian dilakukan di Kabupaten Asahan yang meliputi kecamatan BP Mandoge dan Buntu Pane. Adapun alasan pemilihan lokasi dikarenakan berdasarkan hasil BPS Kabupaten Asahan 2011 menerangkan bahwa kecamatan BP Mandoge dan Buntu Pane merupakan sentra perkebunan kelapa sawit di Kabupaten Asahan.

Pemilihan lokasi kecamatan BP Mandoge dan Buntu Pane dikarenakan oleh kecamatan tersebut merupakan perkebunan mayoritas yang dimiliki oleh perusahaan besar yang memiliki kecendrungan mengalami perkembangan. Pada Kecamatan Buntu Pane areal perkebunan mayoritas digarap oleh PT. Perkebunan Nusantara III (Persero) dan PT. Perkebunan Nusantara IV (Persero) pada Kecamatan BP. Mandoge. Penelitian ini dilaksanakan pada bulan Februari - April 2012.

Pada penelitian menggunakan metode penelitian deskriptif, yang dimaksud dengan penelitian deskriptif menurut kuncoro (2003) adalah pengujian data untuk menguji hipotesis atau menjawab pertanyaan mengenai status terakhir dari subjek penelitian. Pendekatan yang dilakukan dalam penelitian ini adalah studi kasus dengan didukung metode survey. Penelitian survey menurut sugiono (2002) adalah penelitian yang dilakukan pada sebuah populasi tetapi data yang dipelajari merupakan data dari sampel yang diambil dari populasi tersebut.

Populasi adalah jumlah keseluruhan dari unit analisis yang ciri - cirinya sudah diduga. Populasi atau Responden yang diambil pada penelitian ini adalah masyarakat 
yang terdapat di Kecamatan BP Mandoge dan Buntu Pane Kabupaten Asahan, Propinsi Sumatera Utara. Adapun jumlah penduduk di Kecamatan BP Mandoge sebesar 32.845 orang dan Buntu Pane sebesar 22.538 orang sehingga total populasi sebesar 55.383 orang.

Sampel penelitian adalah bagian dari populasi yang mendapatkan perlakuan sama dalam penelitian dan secara keseluruhan mempunyai sifat yang sama dengan populasi. Sebuah sampel haruslah sedemikian rupa sehingga setiap satuan elementer mempunyai kesempatan dan peluang yang sama untuk dipilih dan besarnya peluang tersebut tidak boleh sama dengan nol (Mantra, et al, dalam Tarmidi, 2007)

Metode penarikan sampel pada penelitian ini merupakan pengambilan sampel secara acak (Random Sampling) dan pengambilan jumlah sampel dengan menggunakan rumus Taro Yamane yang dikutip oleh Rakhmat (1998). Adapun uraian rumus sebagai berikut:

$$
\mathrm{n}=\frac{N}{N \cdot d^{2}+1}
$$

Keterangan:

$\mathrm{n}$ = Jumlah Sampel

$\mathrm{N}$ = Jumlah Populasi

$\mathrm{d}^{2}=$ Persen kelonggaran ketidaktelitian/kesalahan dalam pengambilan sampel yang masih dapat ditolerir atau diinginkan. Pada penelitian ini digunakan $\mathrm{d}^{2}$ sebesar 15 $\%$.

Berdasarkan rumus, Maka diperoleh sampel sebesar 44 orang, adapun uraiannya sebagai berikut:

$$
\begin{aligned}
& \mathrm{n}=\frac{55.383}{55.383(0,15)^{2}+1} \\
& \mathrm{n}=44 \text { Orang }
\end{aligned}
$$


Adapun pembagian jumlah sampel pada masing-masing kecamatan diuraikan pada Tabel 2.

Tabel 2. Sebaran Jumlah Sampel Pada Masing-Masing Kecamatan

\begin{tabular}{|l|l|l|l|}
\hline No & Kecamatan & $\begin{array}{l}\text { Persentase Jumlah Penduduk dari } \\
\text { kedua Kecamatan }\end{array}$ & Jumlah Sampel \\
\hline 1 & BP Mandoge & $59 \%$ & 26 orang \\
\hline 2 & Buntu Pane & $41 \%$ & 18 orang \\
\hline Jumlah & \multicolumn{2}{|c|}{44 orang } \\
\hline
\end{tabular}

Sumber: Data diolah, 2012

Pada penelitian ini, pengumpulan data dilakukan dengan mengadakan wawancara langsung (face to face interview) kepada responden/Masyarakat. Wawancara dilakukan dengan panduan daftar pertanyaan atau kuesioner yang terstruktur (structured questionnaire).

Jenis pertanyaan yang digunakan dalam kuesioner merupakan pertanyaan non terstruktur (terbuka) dan pertanyaan terstruktur (tertutup). Pertanyaan terstruktur (tertutup) adalah pertanyaan yang dibuat sedemikian rupa sehingga responden/masyarakat dibatasi untuk memberi jawaban kepada beberapa alternatif jawaban tertentu.

Data primer yang telah dikumpulkan melalui kuesioner terlebih dahulu diklasifikasi, ditabulasi, dan selanjutnya dioiah sesuai dengan alat analisis yang dipakai, diantaranya:

Dampak perkebunan kelapa sawit terhadap income (pendapatan) masyarakat di kabupaten Asahan dengan menggunakan rumusan analisis pendapatan. Dalam usahatani kelapa sawit penerimaan merupakan perkalian antara produksi dengan harga jual.

$\mathrm{TR}=\mathrm{Yi}$. Py

$$
\begin{aligned}
& \text { TR = Total Penerimaan } \\
& \text { Yi = Produksi yang diperoleh } \\
& \text { Py = Harga Y }
\end{aligned}
$$

Biaya Usahatani adalah semua pengeluaran yang dipergunakan dalam suatu usahatani

$$
\begin{aligned}
\mathrm{TC} & =\mathrm{FC}+\mathrm{VC} \\
\mathrm{TC}=\text { Total Biaya } & \\
\mathrm{FC} & =\text { Biaya Tetap } \\
\mathrm{VC} & =\text { Biaya Tidak Tetap }
\end{aligned}
$$


Pendapatan Usahatani adalah selisih antara penerimaan dan pengeluaran

$\Pi=\mathrm{TR}-\mathrm{TC}$

$\mathrm{TR}=$ Total Penerimaan,

$\mathrm{TC}=$ Total Biaya

R/C adalah Perbandingan antara penerimaan Biaya (Sukartawi, 1991)

Analisis Dampak Perkebunan Kelapa sawit sebelum dan sesudah berkembangnya perkebunan kelapa sawit dengan menggunakan Tes Uji - t Untuk menunjukkan apakah ada perbedaan nyata antara sebelum dan sesudah adanya perkebunan sawit. dilakukan tes uji t. Dengan menggunakan taraf kepercayaan 0,01 (99\%) dan 0,05 (95\%) dimana, $\mathrm{A}=$ Sebelum $\mathrm{B}=$ Sesudah.

Dari hasil uji ini akan terlihat ada atau tidak perbedaan nyata antara sebelum dan sesudah adanya perkebunan kelapa sawit.

$$
\mathbf{t}_{\mathrm{A}-\mathrm{B}}=\frac{\overline{X A}-\overline{X B}}{\sqrt{\frac{S A^{2}}{N A}}+\frac{S B^{2}}{N B}}
$$

Membandingkan Pendapatan Usahatani Kelapa Sawit di Kecamatan Bp Mandoge dan Buntu Pane mampu meningkatkan pendapatan. Kay (1981), mengatakan ukuran yang berhubungan dengan pendapatan usahatani adalah dengan melihat beberapa komponen, rumusan sebagai berikut :

$\mathrm{R} / \mathrm{C}>1$,

Perbandingan antara penerimaan total dengan biaya total lebih besar dari satu $\Pi>0$,

Keuntungan yang diperoleh lebih besar dari nol

п/C х $100 \%$ > tingkat suku bunga bank,

Persentase perbandingan keuntungan dengan biaya lebih besar dari tingkat suku bunga.

\begin{tabular}{|c|c|c|c|c|}
\hline No & Uraian & Bp Mandoge & Buntu Pane & $\begin{array}{l}\text { Hasil Tes } \\
\text { Uji-t }\end{array}$ \\
\hline 1 & $\mathrm{R} / \mathrm{C}$ & & & \\
\hline 2 & $\begin{array}{l}\text { Keuntungan } \\
\text { (Rp/thn) }\end{array}$ & & & \\
\hline 3 & $\begin{array}{l}\Pi / C \times 100 \% \\
(\%)\end{array}$ & & & \\
\hline \multicolumn{5}{|c|}{ TARAF $1 \%, 5 \%$} \\
\hline \multicolumn{5}{|c|}{ 霸 $\mathrm{http}: / /$ mahesainstitute.web.id/ojs2/index.php/jehss } \\
\hline
\end{tabular}

Tabel. 3. Perbandingan Hasil Tes Uji-t Kecamatan Bp Mandoge dan Buntu Pane 
Kontribusi Usahatani Kelapa sawit terhadap Pendapatan Keluarga Petani

$\mathrm{Y}=$ Total Pendapatan Keluarga Petani (Rp/th)

$\mathrm{X}=$ Pendapatan dari Kelapa sawit(Rp/th)

$\mathrm{A}=$ Kontribusi Kelapa sawit $(\mathrm{Rp})$

$\mathrm{A}=\mathrm{X} / \mathrm{Y} \times 100 \%$

Apabila Kontribusinya,

$>75 \%$ besar sekali

50-75 \% besar

$25-49 \%$ cukup

$<25 \%$ kecil (Suratiyah 2002)

\section{HASIL DAN PEMBAHASAN}

Analisis Usahatani perkebunan kelapa sawit sebagai sumber pendapatan petani berdasarkan data survey lapangan pada penelitian ini adalah kecamatan BP. Mandoge dan Buntu Pane. Masing masing kecamatan dihitung berdasarkan analisis finansial menyangkut produksi, harga, penerimaan dan biaya serta pendapatan usahatani.

Sesuai dengan formulasi Sukartawi (2001) Pada analisis finasial usahatani penerimaan merupakan perkalian antara produksi dengan harga jual.

$$
\text { TR = Yi.Py }
$$

$$
\begin{aligned}
& \mathrm{TR}=\text { Total Penerimaan } \\
& \mathrm{Yi}=\text { Produksi yang diperoleh } \\
& \mathrm{Py}=\text { Harga } \mathrm{Y}
\end{aligned}
$$

Sedangkan total biaya merupakan penjumlahan antara biaya tetap dengan biaya variabel, dengan Rumus:

\section{TC=TFC+TVC}

Kemudian pendapatan merupakan selisih Total Penerimaan (TP) dengan Total Biaya (TC) menggunakan Rumus:

$$
\mathbf{I}=\mathbf{T R}-\mathbf{T C} \text {. }
$$

Pada Penelitian ini yang menjadi daerah objek penelitian adalah Kecamatan BP. Mandoge dan Kecamatan Buntu Pane

Kecamatan BP. Mandoge 
Produksi rata-rata sampel sebesar 43 ton sedangkan harga jual yang berlaku Rp. 1.300,- Total yang diperoleh petani sebesar Rp. 55.934.615,- dengan Total biaya sebesar Rp. 13.500.000 dan pendapatan petani sebesar Rp. 42.434.615/tahun.

Kecamatan Buntu Pane

Produksi rata-rata petani sampel sebesar 39 ton, sedangkan harga jual yang berlaku Rp. 1.300,- Total yang diperoleh petani sebesar Rp. 50.697.222,- dengan total biaya sebesar Rp. 13.250.000 dan pendapatan petani sebesar Rp. 37.447.222/tahun

Setelah dilakukan analisis usahatani maka selanjutnya dilakukan analisis pendapatan hasil usaha perkebunan kelapa sawit masyarakat yang terdiri dari seluruh responden. Adapun uraian perhitungan pendapatan petani perkebunan kelapa sawit rakyat di Kabupaten Asahan terdapat pada Tabel 4.

Tabel 4. Rekapitulasi Perhitungan Pendapatan TM Berdasarkan Umur Tanaman/ha/thn

\begin{tabular}{|l|l|l|l|l|c|}
\hline No & $\begin{array}{l}\text { Umur Kelapa } \\
\text { Sawit (Tahun) }\end{array}$ & $\begin{array}{l}\text { Produksi } \\
(\text { Kg) }\end{array}$ & $\begin{array}{l}\text { Penerimaan } \\
(\mathrm{Rp})\end{array}$ & $\begin{array}{l}\text { Biaya Produksi } \\
(\mathrm{Rp})\end{array}$ & Pendapatan (Rp) \\
\hline 1. & 5 & 34.000 & 44.203 .846 & 13.115 .385 & 31.088 .462 \\
\hline 2. & 8 & 48.000 & 62.356 .452 & 13.943 .548 & 48.412 .903 \\
\hline
\end{tabular}

Sumber : Data Primer (Diolah), 2012

\section{Analisis Dampak Perkebunan Kelapa sawit sebelum dan sesudah berkembangnya perkebunan kelapa sawit}

Analisis perbandinagn dampak dari perkembangan perkebunan kelapa sawit sebelum dan sesudah dapat dilakukan dengan menggunakan analisis Uji t terhadap kontribusi usahatani sebelum dan sesudah berkembangnya perkebunan kelapa sawit. Hasil dari analisis Uji t terhadap kontribusi usahatani sebelum dan sesudah berkembangnya perkebunan kelapa sawit ialah:

Sebelum Berkembangnya Perkebunan Kelapa sawit: \% pendapatan usahatani lain terhadap total pendapatan rumah tangga tani (karet, padi, ternak) sebesar $38 \%$

Sesudah Berkembangnya Perkebunan Kelapa Sawit: \% pendapatan usahatani kelapa sawit terhadap total pendapatan rumah tangga tani $62 \%$

Uji t menggunakan Rumus :

\section{tA-B=}

$$
\frac{\overline{X A}-\overline{X B}}{\sqrt{\frac{S A^{2}}{N A}}+\frac{S B^{2}}{N B}}
$$

SA : Keragaman sebelum berkembangnya perkebunan kelapa sawit 
SB : Keragaman sesudah berkembangnya perkebunan kelapa sawit

NA : Jumlah sampel yang di uji

NB : Jumlah sampel yang diuji

Hasil t thitung lebih besar dari t tabel (thit> t tabel)

$(\mathrm{P}<0,01)=2,390$

$(\mathrm{P}>0,05)=1,671$

Berdasarkan hasil uji t, maka dapat disimpulkan bahwa kontribusi perkebunan kelapa sawit sangat signifikan/mempengaruhi terhadap total pendapatan rumah tangga petani yang terdapat di kecamatan BP Mandoge dan buntu Pane Kabupaten Asahan.

\section{Analisis Perbandingan Pendapatan Petani Perkebunan Rakyat Pada 2 (dua) Lokasi Penelitian}

Guna mengetahui pengaruh perolehan pendapatan usatani perkebunan kelapa sawit, maka selanjutnya dilakukan perbandingan dua lokasi penelitian yakni Kecamatan BP Mandoge dan Buntu Pane Kabupaten Asahan. Uraian perbandingan rata-rata pendapatan terdapat pada Tabel 5.

Tabel 5. Perbandingan Pendapatan Petani Kecamatan BP Mandoge dan Buntu Pane

\begin{tabular}{|l|l|l|l|l|}
\hline No & Uraian & Mandoge & Buntu Pane & $\begin{array}{l}\text { Hasil Tes } \\
\text { Uji-t }\end{array}$ \\
\hline 1. & R/C & 2,1 & 1,9 & Thit $>$ t tabel \\
\hline 2. & Keuntungan(ח) (Rp/thn) & 17.500 .000 & 16.980 .000 & Thit $<$ t tabel \\
\hline 3. & ח/C x 100\% (\%) & 21 & 20,8 & Thit $<$ t tabel \\
\hline \multicolumn{5}{|l}{ TARAF 1\%, 5\% }
\end{tabular}

Berdasarkan hasil uraian Tabel 5, maka kecamatan BP. Mandoge dan kecamatan Buntu Pane tidak berbeda nyata. Hal ini mengindikasikan pengaruh perkebunan kelapa sawit sama-sama mempengaruhi terhadap pendapatan dan kehidupan masyrakat sekitar.

\section{Analisis Kontribusi Usahatani Kelapa Sawit Terhadap Total Pendapatan}

Kontribusi usahatani perkebunan kelapa sawit terhadap total pendapatan keluarga di Kabupaten Asahan termasuk besar. Kontribusi usahatani yang diperolaeh dengan melihat Total Pendapatan keluarga Petani diperoleh dari :

$Y=a 1+a 2+a 3+a 4$

a1 = Pendapatan usahatani kelapa sawit

a2 = Pendapatan usahtani selain kelapa sawit seperti kelapa, karet, padi, ayam

30. $\mathrm{http}: / /$ mahesainstitute.web.id/ojs2/index.php/jehss

Nmahesainstitut@gmail.com 
Vol 2, No. 2, Desember 2019, DOI: https://doi.org/10.34007/iehss.v2i2.109

a3 = Luas usahatani pertanian seperti buruh di sawah, buruh peternakan

a4 = Non pertanian seperti tukang, karyawan, swasta, PNS

$\mathrm{Y}=$ Total Pendapatan Keluarga Petani (Rp/th)

$\mathrm{X}=$ Pendapatan dari Kelapa sawit(Rp/th)

$\mathrm{A}=$ Kontribusi Kelapa sawit (\%)

$\mathrm{A}=\mathrm{X} / \mathrm{Y} \times 100 \%$

Pada penelitian ini diperoleh $62 \%$ dari total pendapatan keluarga petani, sehingga dikatakan kontribusi perkebunan kelapa sawit besar sesuai dengan kriteria kontribusi sebesar 50-75 \% dikategorikan besar

\section{SIMPULAN}

Perkebunan kelapa sawit memberikan pengaruh sangat signifikan terhadap pendapatan rumah tangga petani yang terdapat di kecamatan BP Mandoge dan Buntu Pane Kabupaten Asahan. Berdasarkan kriteria pengembangan menggunakan R/C, besarnya keuntungan, dan melihat tingkat suku bunga bank, Kecamatan BP Mandoge lebih tinggi dari kecamatan Buntu Pane. Kontribusi perkebunan kelapa sawit memberikan pengaruh besar terhadap income masyarakat. Sebesar $62 \%$ dari total pendapatan keluarga petani berasal dari perkebunan sawit.

\section{DAFTAR PUSTAKA}

Alma, B. (2010). Belajar Mudah Penelitian. Alfabeta. Bandung.

Arman, R., Hariyadi \& Sunito, S. (2017), Kelentingan Penghidupan Rumah Tangga Eks Buruh Harian Lepas Perkebunan Kelapa Sawit di Desa Sei Mangkei, Agrica (Jurnal Agribisnis Sumatera Utara), 10 (1): 3663

Arsyad, L. (1999). Ekonomi Pembangunan. Yogyakarta: Bagian Penerbitan STIE YKPN.

Bangun, R.H. (2013), Kajian Potensi Perkebunan Rakyat di Provinsi Sumatera Utara Menggunakan Location Quotient dan Shift Share, Agrica (Jurnal Agribisnis Sumatera Utara), 6(2) 2: 103-109

Departemen Pertanian. (2000). Statistik Perkebunan Indonesia. Departemen Pertanian. Jakarta.

Departemen Pertanian. (2002). Statistik Perkebunan Indonesia. Jakarta: Departemen Pertanian. Jakarta.

Departemen Pertanian. (2008). Statistik Perkebunan Indonesia. Jakarta: Departemen Pertanian. Jakarta.

Departemen Pertanian. (2010). Statistik Perkebunan Indonesia. Jakarta: Departemen Pertanian. Jakarta.

Kadir, A. \& Pane, R.A.H. (2018a). Evaluasi Kinerja Pegawai Bagian Program Kemitraan Dan Bina Lingkungan Pada PT. Perkebunan Nusantara III (Persero) Medan. JUPIIS: Jurnal Pendidikan Ilmuilmu Sosial, Vol. 10(2): 205-209.

Kadir, A. (2018b). Analisis Penetapan Nilai Jual Obyek Pajak Bumi dan Bangunan Sektor Perkebunan sebagai Upaya Peningkatan Sumber Pendapatan Daerah. Journal of Education, Humaniora and Social Sciences (JEHSS). 1(1): 9-15.

Lubis, F.R.A. \& Tinaprilla, N. (2017), Sistem Tataniaga Tandan Buah Segar di Kecamatan Wampu, Kabupaten Langkat, Sumatera Utara, Agrica (Jurnal Agribisnis Sumatera Utara), 10(1): 126-139

Rahman, A. \& Sembiring, S. (2017), Peningkatan Daya Saing Dan Analisis Kelayakan Usahaternak Domba Pada Perkebunan Kelapa Sawit di Kabupaten Asahan, Agrica (Jurnal Agribisnis Sumatera Utara), 10(1): 101-114 
Rahmanta \& Sihombing, N.T. (2008). Dampak Kenaikan Harga Kedelai Terhadap Pendapatan Industri Pengolahan Tempe Di Kota Medan, Agrica (Jurnal Agribisnis Sumatera Utara), 1(2).

Setiawan, K. \& Sengadji, H.M. (2016). Analisis Dampak Kebijakan Pemerintah Terhadap Daya Saing Komoditas Kelapa Di Kabupaten Flores Timur, Agrica (Jurnal Agribisnis Sumatera Utara), 9(2): 8089

Siregar, M.A. (2016), Analisis Lapangan Kerja Sektoral Di Propinsi Sumatera Utara, Agrica (Jurnal Agribisnis Sumatera Utara), 9(2): 126 